somewhere in Africa 100,000 years ago was a woman, a primaeval Earth Mother and the ancestor of us all. Eve (who else?) became the biggest media superstar who never was. A 1980s woman of the Stone Age, she raised the children and supported a career gathering eco-friendly vegetarian wholefoods, and tolerated men for as long as it took to assure the future of her own mitochondria, but not a moment longer. Adam, one notes, never gets a mention. Fagan, to his credit, baulks at the notion of a single Eve figure who is identifiable as such. "In the sense that there was once a single person one could point to as the identifiable, single ancestor of Homo sapiens, the answer is no" he says (page 32). But a few sentences on, he notes that "there may, indeed, once have been a single Eve, but we can never hope to identify her in person".

Fagan's taxonomy, too, is woolly. The formal differences between Homo erectus, Homo sapiens and Homo sapiens sapiens are never made clear, apart from a note that the line between $H$. erectus and $H$. sapiens is hard to draw. One might have thought that rigorous definitions of all taxa concerned would have been essential. It could be that there are no agreed answers to this, in which case Fagan should have been much more explicit about the taxonomic problems posed by traditional archaeological methods.

Traditional archaeology, though, finds Fagan on home turf. His discussion on toolmaking among early $H$. sapiens in Africa was absorbing, partly because it seemed so new. Australopithecus, $H$. habilis and the Leakeys have cast such long shadows over African palaeoanthropology that it was refreshing to be reminded of sites such as Broken Hill and Klasies River Mouth. Identifying workmen from their tools, though, is rather fraught, a bit like divining the breed of a cat from its smile. The only taxonomy here is cultural, and this is dangerous. Referring to the early colonization of Australasia by boat (page 137), Fagan says that "the expertise to cross water out of sight of land, however accidental initially, was a distinctive skill of Homo sapiens sapiens". Maybe, but only if we find one buried with a map and compass.

The Journey from Eden is hobbled by a casual attitude too reticent to question assumptions that have a central bearing on the book's entire theme. Frequent lapses of consistency and logic - not to mention style - suggest a book written in a hurry. To document the spread of modern humanity is a worthy aim, and it deserves a far more measured and critical appraisal. Clear thinking and attention to detail are two victorian values worth keeping: for the same money, Picasso would have given you two heads.

Henry Gee is on the editorial staff of Nature.
Good time guide

Michael McElhinny

A Geologic Time Scale 1989. By W. B Harland, R. L. Armstrong, A. V. Cox, L. E Craig, A. G. Smith and D. G. Smith. Cambridge University Press: 1990. Pp. 263. Hbk £25, \$49.50; pbk £11.95, \$19.95.

IN the earth sciences the study of time is one of the most fundamental endeavours necessary for the development of almost all aspects of the science. There have been many successive attempts by various authors to produce definitive time scales covering the whole of Earth history, perhaps the most notable of these being $A$ Geologic Time Scale 1982 by Harland and coauthors, the predecessor of this book. The new and updated version is quite outstanding and represents a model of scientific synthesis and presentation.

The work develops and assesses a new calibration of the geological time scale using a new database up to 1988 . It adopts the same style and uses and develops similar methods to the previous volume, but it has been entirely reworked. It should be noted that the 1982 Time Scale was based mostly on data compiled before 1976 . The 1989 Time Scale, however, not only presents the state of the art in 1989 but the data assembled provide a source of reference which will serve for some years. The list of nearly 1,000 cited and other references provides an excellent bibliography.

Some of the most important and significant aspects of this volume relate to the way in which the database of isotopic determinations has been refined by tests both stratigraphic and geochemical. Many of the age determinations used for the 1982 Time Scale have been rejected and the database now includes Cenozoic data (previously the Hardenbol and Berggren Cenozoic scale of 1978 was simply incorporated unchanged). About 700 isotopic determinations are listed. The chronostratic scale is calibrated applying and developing the chronogram method introduced with the 1982 Time Scale and based on the method used to estimate the ages of magnetic reversals from radiometric data. The process resulted in 127 chronograms of which 125 are reproduced in an appendix. A major advantage of this method is that a new scale can be produced automatically in a few hours incorporating new data and varying the data input. This allows comparison of the effects of the inclusion and exclusion of different classes of data. Finally the magnetostratigraphic scale has been updated and this in turn enables some refinement to the resulting time scale.

By showing the method of construction the reader can assess how the new time scale may be modified as more critical data become available. The estimated uncertainties in the time scale values adopted are significantly less than in previously published estimates. Changes from the 1982 Time Scale are most significant in the Jurassic-Triassic and during the Upper Carboniferous. The base of the Cambrian has been reduced from 590 to 570 Myr BP and seems likely to be reduced further in the future. The Vendian has been given substantial treatment, resulting in a reduction of the estimated age of its base from 670 to $610 \mathrm{Myr} \mathrm{BP}$.

This work will be of fundamental importance to almost every earth scientist and I highly recommend it to all both as compulsory reading and as an essential part of their personal library. A newly designed coloured wall chart of the 1989 Time Scale is also available as a separate publication and is the sort of thing one could expect to see on the wall of everyone's office.

Michael W. McElhinny, Gondwana Consultants Pty Limited, 112 Sealand Road, Fishing Point, New South Wales 2283, Australia.

\section{Critical errors}

\section{Ted Forgan}

Fundamentals of Superconductivity. By V. Z. Kresin and S. A. Wolf. Plenum: 1990. Pp. 231. $\$ 42.50$.

THERE must be many readers, intrigued by the phenomenon of high-transitiontemperature (high- $T$ ) superconductivity, who would be interested in a book which introduces superconductivity and explains the significance of the new high- $T_{c}$ materials. With the title Fundamentals of Superconductivity, and the claim in the preface that it is aimed at a broad audience, Kresin and Wolf's book might appear to fulfill this need.

The authors state that they have concentrated on the qualitative aspects, so that the reader will not get bogged down in details. To me, many of their explanations seem not so much qualitative as slipshod, particularly in the theory chapters. For instance, to demonstrate the existence of the superconducting energy gap, the authors quote formulae for the lowtemperature heat capacity, but do so on three separate occasions, and each time give a different formula. The reader is left unsure whether only two or all three of these formulae are incorrect. There are also startling changes in the difficulty and degree of explanation: advanced topics appear without warning next to laboured treatments of basic ideas.

On too many occasions, confusion is caused by misprints in text and equations, and a few of the diagrams are rendered almost incomprehensible by inadequate 